\title{
Submillisecond Optogenetic Control of Neuronal Firing with Two-Photon Holographic Photoactivation of Chronos
}

\author{
Emiliano Ronzitti, ${ }^{1}$ Rossella Conti, ${ }^{1}$ Valeria Zampini, ${ }^{1}$ Dimitrii Tanese, ${ }^{1}$ Amanda J. Foust, ${ }^{1}$ Nathan Klapoetke,, 3 \\ Edward S. Boyden, ${ }^{3}$ Eirini Papagiakoumou, ${ }^{1,2}$ and Valentina Emiliani ${ }^{1}$ \\ ${ }^{1}$ Neurophotonics Laboratory, Wavefront Engineering Microscopy Group, Centre National de la Recherche Scientifique (CNRS), Unité Mixte de Recherche \\ (UMR) 8250, Université Paris Descartes, 75270 Paris Cedex 06, France, ${ }^{2}$ Institut National de la Santé et de la Recherche Médicale (INSERM), 75013 Paris, \\ France, ${ }^{3}$ Media Laboratory and McGovern Institute, Departments of Biological Engineering and Brain and Cognitive Sciences, Massachusetts Institute of \\ Technology, Cambridge, Massachusetts 02139, and 4Janelia Research Campus, Howard Hughes Medical Institute, Ashburn, Virginia 20147
}

Optogenetic neuronal network manipulation promises to unravel a long-standing mystery in neuroscience: how does microcircuit activity relate causally to behavioral and pathological states? The challenge to evoke spikes with high spatial and temporal complexity necessitates further joint development of light-delivery approaches and custom opsins. Two-photon (2P) light-targeting strategies demonstrated in-depth generation of action potentials in photosensitive neurons both in vitro and in vivo, but thus far lack the temporal precision necessary to induce precisely timed spiking events. Here, we show that efficient current integration enabled by $2 \mathrm{P}$ holographic amplified laser illumination of Chronos, a highly light-sensitive and fast opsin, can evoke spikes with submillisecond precision and repeated firing up to $100 \mathrm{~Hz}$ in brain slices from Swiss male mice. These results pave the way for optogenetic manipulation with the spatial and temporal sophistication necessary to mimic natural microcircuit activity.

Key words: holography; optogenetics; two-photon excitation

Significance Statement

To reveal causal links between neuronal activity and behavior, it is necessary to develop experimental strategies to induce spatially and temporally sophisticated perturbation of network microcircuits. Two-photon computer generated holography (2P-CGH) recently demonstrated 3D optogenetic control of selected pools of neurons with single-cell accuracy in depth in the brain. Here, we show that exciting the fast opsin Chronos with amplified laser 2P-CGH enables cellular-resolution targeting with unprecedented temporal control, driving spiking up to $100 \mathrm{~Hz}$ with submillisecond onset precision using low laser power densities. This system achieves a unique combination of spatial flexibility and temporal precision needed to pattern optogenetically inputs that mimic natural neuronal network activity patterns.

\section{Introduction}

Optogenetic manipulation of neuronal excitation and inhibition (Boyden et al., 2005; Yizhar et al., 2011a) has the potential to

Received May 6, 2017; revised Sept. 14, 2017; accepted Sept. 16, 2017.

Author contributions: V.E. designed research; E.R., R.C., V.Z., D.T., A.J.F., and E.P. performed research; N.K. and E.S.B. contributed unpublished reagents/analytic tools; E.R. and R.C. analyzed data; E.R., A.J.F., and V.E. wrote the paper.

This work was supported by the Agence Nationale de la Recherche (Grants ANR-10-INBS-0401 and ANR-14-CE130016), the National Institute of Health (Grant 1-U01-NS090501-01), the Getty Lab, the Medical Research Foundation (Grant DVS20131228920), the Federation pour la Recherche sur le Cervau (FRC), the Rotary Club through the program Espoir en Tete 2012, the Human Frontier Science Program (Grant RGP0015/2016), and a National Science Foundation International Postdoctoral Research Fellowship (A.J.F.). We thank Marta Gajowa and Fabio SimonyConesa for help in mice viral injections; Christophe Tourain for technical support in building the holographic system; Vincent de Sars for software development; Cecile Jouffret for help in cell culture maintenance.

The authors declare no competing financial interests.

Correspondence should be addressed to Valentina Emiliani, Neurophotonics Laboratory, Wave Front Engineering Microscopy Group, CNRS UMR8250, Université Paris Descartes, 45 Rue des Saints Pères, 75270 Paris Cedex 06, France. E-mail:valentina.emiliani@parisdescartes.fr. increase exponentially neuroscience's capacity to elucidate causal relationships between neural circuits and behavior (O'Connor et al., 2009). Reaching this goal depends on developing methods to manipulate neurons in spatiotemporal patterns that mimic physiological neuronal network activity, which necessitates single-cell optical control of spiking at high firing rates with submillisecond temporal precision (Lin, 2011; Peron and Svoboda, 2011). These goals necessitate the parallel development of fast and highly light-sensitive opsins and sophisticated light-delivery approaches.

Recently engineered channelrhodopsin variants (Gunaydin et al., 2010; Berndt et al., 2011; Klapoetke et al., 2014) have improved light-gated channel kinetics significantly while maintaining high light sensitivity. Fast opsins such as ChETA and Chronos 
exhibit conducting state lifetimes nearly two to three times shorter than conventional ChR2 (Gunaydin et al., 2010; Klapoetke et al., 2014). Combined with single-photon (1P) wide-field illumination, these opsins enabled sustained and precisely timed firing over a range of frequencies from 5 to $200 \mathrm{~Hz}$ both in cultured neurons and acute brain slices (Gunaydin et al., 2010; Klapoetke et al., 2014), with major improvements in terms of spike reliability and reduction of artifactual spikes and plateau potential during extended light trains.

Due to the lack of axial confinement and limited penetration depth of $1 \mathrm{P}$ wide-field illumination, in depth, neuron-resolution optogenetic control requires confined soma-targeted two-photon (2P) illumination. 2P single-cell photostimulation can be achieved either by scanning a focused 2P laser beam (Rickgauer and Tank, 2009; Packer et al., 2012, 2015; Prakash et al., 2012) or by generating 2P-parallel illumination patterns using computer-generated holography (CGH), generalized phase contrast (GPC), and low-NA Gaussian beams combined with temporal focusing ( $\mathrm{Pa}-$ pagiakoumou et al., 2010; Bègue et al., 2013; Rickgauer et al., 2014; Chaigneau et al., 2016).

Scanning approaches rely mainly on slow opsins (i.e., C1V1; Yizhar et al., 2011b) with currents that temporally sum during the scan to reach spike threshold. Scanning thus necessitates a trade-off between scan time and temporal current integration of the light-gated channels serially illuminated across a cell. Evoking action potentials (APs) with scanning approaches required so far illumination durations ranging from 5 to $70 \mathrm{~ms}$ to achieve $6-20 \mathrm{~ms}$ AP onset jitter (Packer et al., 2012, 2015; Prakash et al., 2012) and AP rates up to $40 \mathrm{~Hz}$ (Prakash et al., 2012).

Parallel light-delivery approaches simultaneously actuate currents from every opsin in the cell membrane, integrating spatially to bring the neuron quickly to spike threshold. While scanning approaches necessitate slow-off kinetic opsins for temporal integration, parallel light delivery modalities enable spike with comparable latency and onset accuracy using either slow or fast opsins (Papagiakoumou et al., 2010; Bègue et al., 2013; Chaigneau et al., 2016). Parallel illumination of conventional ChR2 (Papagiakoumou et al., 2010) and slow opsins such as C1V1 (Bègue et al., 2013) and ReaChR (Chaigneau et al., 2016) have shown firing at up to 20-30 $\mathrm{Hz}$ spike rates. They are also susceptible to spike time variation and generation of spurious extra spikes. These shortcomings arise from opsins limited kinetics. Indeed, high-frequency, light-driven AP trains require opsins with rapid off kinetics for fast membrane repolarization and inactivation recovery after each spike.

These considerations indicate $2 \mathrm{P}$ parallel photostimulation of fast opsins as the optimal strategy for in-depth optical control of neural firing with high precise spatiotemporal precision. Here, we characterize the $2 \mathrm{P}$ action spectrum and kinetics of the fast opsin Chronos (Klapoetke et al., 2014) with holographically shaped light pulses. We demonstrate efficient current integration with $2 \mathrm{P}$ parallel illumination, enabling AP generation with submillisecond temporal precision and neuronal spike frequencies up to $100 \mathrm{~Hz}$. Importantly, we used a fiberamplifier, high-energy pulse laser to reduce average illumination power drastically. Our results highlight the potential of this approach to mimic a broad range of physiological firing patterns with submillisecond temporal precision, key to analyzing how specific patterns of network activity contribute to behavior and pathological states.

\section{Materials and Methods}

\section{Imaging and photostimulation setup}

The optical system was built around a commercial upright microscope (SliceScope; Scientifica) and combined a multi-light-path imaging architecture with a holographic-based photoactivation apparatus.

The imaging system was composed of three different imaging pathways: a $2 \mathrm{P}$ raster scanning, a $1 \mathrm{P}$ wide-field epifluorescence, and an infrared (IR) off-center oblique illumination imaging (see Fig. 1a).

2P imaging was provided by a mode-locked Ti-Sapphire source (Coherent Chameleon Vision II, pulse width $140 \mathrm{fs}$, tuning range 680-1080 nm). The femtosecond pulsed beam was raster scanned on the sample via a pair of XY galvanometric mirrors (3 mm aperture, $6215 \mathrm{H}$ series; Cambridge Technology) imaged at the back aperture of the microscope objective ( $40 \times$ W APO NIR; Nikon) through an afocal telescope (scan lens: $f=100 \mathrm{~mm}$; Thorlabs \#AC508-300-B; tube lens: $f=300 \mathrm{~mm}$; Thorlabs \#AC508-100-B). Galvanometric mirrors were driven by two servo drivers (MicroMax series 671; Cambridge Technology) controlled by a digital/analog converter board (PCI-6110; National Instrument). Emitted fluorescence was collected by a fiber-coupled detection scheme (Ducros et al., 2011) including a large diameter collector lens ( $f=75 \mathrm{~mm}$; Thorlabs \#LB1309-A) and a 5-mm-diameter liquid light guide (Lumatec Series 300 customized with an $f=14.5 \mathrm{~mm}$ doublet lens glued at the fiber entrance by Till Photonics and an anti-reflective coating provided at the fiber exit). The fiber exit was imaged onto two photomultiplier tubes (PMT) GaAsP (H10770-40 SEL; Hamamatsu \#H10770-40 SEL) by a set of three matching aspheres lenses ( $f=23.5 \mathrm{~mm}$; Melles Griot \#LAG32.5-23.5-C). After the fiber exit, fluorescence light was filtered by two IR-light blocking filters (Semrock \#FF01-750sp), split into two channels by a dichroic mirror (Semrock \#FF555-Di03) and detected through two emission filters (Semrock \#FF01-510/84 and \#FF02-617/73).2P imaging laser power was tuned by combining an electrically controlled liquid crystal variable phase retarder (Meadowlark Optics \#LRC-200-IR1) and a polarizer cube (Meadowlark Optics \#BB-050-IR1).

$1 \mathrm{P}$ imaging was provided by a LED source (Thorlabs \#M470L2) filtered by a bandwidth excitation filter (Semrock \#FF01-452/45) and coupled to a diffuser (Thorlabs \#DG10-1500) and an achromatic lens ( $f=$ $30 \mathrm{~mm}$, \#LA1805 Thorlabs) to provide widefield illumination on the sample. 1P excited fluorescence was collected through a tube lens ( $f=$ $200 \mathrm{~mm}$ ), separated from $1 \mathrm{P}$ excitation light using a dichroic mirror (Semrock \#FF510-Di02) and detected by a charge-coupled device (CCD) camera (Hamamatsu Orca-05G) after passing through a visible bandwidth filter (Semrock FF01-609/181).

The collection of the fluorescence induced by $2 \mathrm{P}$ raster scanning or $1 \mathrm{P}$ wide-field illumination through either PMTs or CCD, respectively, is ensured by the presence in the fluorescence detection pathway of a downstream movable dichroic mirror $(70 \times 50 \mathrm{~mm}$ custom size; Semrock \#FF705-Di01) and an upstream dichroic mirror (Chroma \#ZT670rdc-xxrxt).

IR oblique illumination imaging was provided by an IR-LED source (Thorlabs \#M780L2) installed at the rear port of the microscope coupled with a condenser focusing the light on the sample. IR light transmitted through the sample was collected with an IR CCD (DAGEMIT IR-1000).

$2 \mathrm{P}$ photoactivation was performed by generating arbitrary light shapes selectively matching specific opsin-tagged patterns in the sample via a spatially controlled phase modulation of the illumination beam wave front. In particular, a femtosecond pulsed beam delivered by a diode pumped, fiber amplifier system (Amplitude Systemes Satsuma HP; pulse width $250 \mathrm{fs}$, tunable repetition rate $500-2000 \mathrm{kHz}$, gated from single shot up to $2000 \mathrm{kHz}$ with an external modulator, maximum pulse energy $20 \mu \mathrm{J}$, maximum average power $10 \mathrm{~W}$, wavelength $\lambda=1030 \mathrm{~nm}$ ) operated at $500 \mathrm{kHz}$, was widened through an expanding telescope and reflected on the sensitive area of a reconfigurable liquid crystal on silicon spatial light modulator (SLM) (Hamamatsu Photonics LCOS-SLM \#X10468-07). The reflected beam was projected at the back focal plane of the objective with an afocal telescope $(f=300 \mathrm{~mm}$; Thorlabs \#AC508$300-\mathrm{B}$ and $f=500 \mathrm{~mm}$ Thorlabs \#AC508-500-B). The SLM was controlled by custom-designed software (Lutz et al., 2008) based on a Gerchberg and Saxton iterative algorithm (Gerchberg and Saxton, 1972), 
which converts an arbitrary intensity pattern on the sample plane to a specific phase profile to be addressed at the SLM plane. The effect of the zero order of diffraction in the sample was suppressed by introducing a cylindrical lens (Hernandez et al., 2014).

$2 \mathrm{P}$ imaging scan and $2 \mathrm{P}$ photoactivation beams were combined through a large dichroic mirror $(50 \times 70 \mathrm{~mm}$; Chroma \#T970dcspxr).

Intensity patterns matching the cellular surface were used for photoactivation of Chinese hamster ovary ( $\mathrm{CHO}$ ) cells, whereas holographich circular spots of $10-20 \mu \mathrm{m}$ were used to photoactivate neurons. Power densities herein are given at the output of the objective and calculated referring to the excitation spot's surface.

\section{Cell line culture and electrophysiology}

$\mathrm{CHO}$ cells were cultured in an incubator at $32^{\circ} \mathrm{C}$ and $5 \% \mathrm{CO}_{2}$ in a D-MEM/F12 GlutaMAX medium (Life Technologies) with the addition of $1 \mathrm{~mm}$ glutamine, $1 \%$ streptomycin, and $10 \%$ fetal bovine serum. Cells were plated on Thermanox plastic coverslips (Thermo Fisher Scientific) $24 \mathrm{~h}$ before transfection. Cells were transfected with a homemade plasmid (FCK-Gene90-GFP provided by Ed Boyden's laboratory) containing the Chronos opsin bound to GFP. The DNA was transfected using the ExGen 500 (Euromedex) transfection reagent and cells were recorded $24-48 \mathrm{~h}$ after transfection. Cultured cells were transferred for recording in a chamber mounted on the headstage of the microscope. Recordings were performed at room temperature. The extracellular medium during electrical recording contained the following (in mM): $140 \mathrm{NaCl}, 5 \mathrm{KCl}, 2$ $\mathrm{CaCl}_{2}, 1 \mathrm{MgCl}_{2}, 20$ HEPES, and 25 glucose, $\mathrm{pH}$ adjusted to 7.5 by $\mathrm{NaOH}$. Electrophysiological recordings were performed through a Multiclamp 700B Amplifier (Molecular Devices) in the whole-cell voltage-clamp recording configuration. Patch pipettes, pulled from borosilicate glass capillaries, had a resistance in the bath that ranged from 4 to $6 \mathrm{M} \Omega \mathrm{s}$. Intracellular solution was composed of the following (in mM): $140 \mathrm{KCl}, 2$ $\mathrm{MgCl}_{2}, 2 \mathrm{Mg}$ ATP, $0.4 \mathrm{Na}$ GTP, 10 HEPES, and 20 BAPTA, pH adjusted to 7.3 and osmolarity 330 . Cells were maintained at $-40 \mathrm{mV}$ throughout recordings. The holding current ranged from 0.8 to $80 \mathrm{pA}$.

\section{Stereotaxic injections of viral vector}

All experimental procedures were approved by the Paris Descartes Ethics Committee for Animal Research (Registered Number CEEA34.EV.118.12) and followed European Union and Institutional guidelines for laboratory animals care and use (Council Directive 86/609 EEC). Stereotaxic injections of the viral vector rAAV8/Synapsin-ChR90-GFP (University of North Carolina Vector Core) were performed in 4-week-old Swiss male mice (Janvier laboratory). Mice were anesthetized with ketamine ( 80 $\mathrm{mg} / \mathrm{kg})$-xylazine $(5 \mathrm{mg} / \mathrm{kg})$ solution and a small craniotomy $(0.7 \mathrm{~mm})$ was made on the skull overlying V1 cortex. Injection of $1-1.5 \mu \mathrm{l}$ of solution containing the viral vector was made with a cannula at $\sim 80-100$ $\mathrm{nl} / \mathrm{min}$ at $200-250 \mu \mathrm{m}$ below the dural surface. The craniotomy and the skull were sutured and the mouse recovered from anesthesia. The combination of our injection protocol and the viral vector used, resulted in a higher percentage of opsin-expressing interneurons with respect to pyramidal cells. Moreover, in the latter, the level of expression was relatively low, as can be seen from the data in Table 1. In pyramidal cells, we had to double the illuminated surface (surface diameter from $10-15 \mu \mathrm{m}$ for interneurons to $15-20 \mu \mathrm{m}$ for pyramidal cells) to obtain similar average photocurrents.

\section{Acute slice preparation and electrophysiology}

Acute parasagittal slices of the visual cortex were made from adult mice 6-8 weeks after viral injection. Animals were decapitated after being anesthetized with isofluorane. The brain was quickly removed and put in an ice-cold sucrose cutting solution containing the following (in $\mathrm{mM}$ ): 85 $\mathrm{NaCl}, 65$ sucrose, $2.5 \mathrm{KCl}, 0.5 \mathrm{CaCl}_{2}, 4 \mathrm{MgCl}_{2}$, and 25 glucose, $\mathrm{pH} 7.4$, saturated with $95 \% \mathrm{O}_{2}$ and $5 \% \mathrm{CO}_{2}$.

The brain was dissected and $300-\mu \mathrm{m}$-thick slices were cut on a vibratome (Leica Biosystems VT1200S). Slices were maintained at $32^{\circ} \mathrm{C}$ for 30 min in standard ACSF (sACSF) containing the following (in mM): 125 $\mathrm{NaCl}, 2.5 \mathrm{KCl}, 26 \mathrm{NaHCO}_{3}, 1.25 \mathrm{NaH}_{2} \mathrm{PO}_{4}, 1 \mathrm{MgCl}_{2}, 1.5 \mathrm{CaCl}_{2}, 25$ glucose, and 0.5 ascorbic acid saturated with $95 \% \mathrm{O}_{2}$ and $5 \% \mathrm{CO}_{2}$ and then transferred at room temperature in the same solution until use. During the experiments, the slices were kept in a chamber and perfused continuously with fresh sACSF saturated with $95 \% \mathrm{O}_{2}$ and $5 \% \mathrm{CO}_{2}$. Cells were patched between 30 to $60 \mu \mathrm{m}$ from the slice surface because more superficial cells are potentially damaged during slicing. The pipette solutions contained the following (in $\mathrm{mm}$ ): $130 \mathrm{~K}$-gluconate, $7 \mathrm{KCl}, 4$ MgATP, 0.3 GTP, 10 phosphocreatine-Na, and 10 HEPES, pH 7.2 with $\mathrm{KOH}$. Borosilicate glass pipette resistance in the bath was $8-12 \mathrm{M} \Omega$ s. Series resistances ranged between 20 and $40 \mathrm{M} \Omega$ s (average: $30 \pm 7 \mathrm{M} \Omega \mathrm{s}$ ) and were compensated for by $60-70 \%$. For interneuron recordings, input resistance ranged between 105 and $520 \mathrm{M} \Omega$ s (average: $220 \pm 100 \mathrm{M} \Omega$ s), membrane capacitance ranged between 18 and $79 \mathrm{pF}$ (average: $37 \pm 15 \mathrm{pF}$ ), and membrane resting potential ranged between -54 and $-76 \mathrm{mV}$ (average: $-65 \pm 5 \mathrm{mV}$ ). For pyramidal cell recordings, input resistance ranged between 172 and $770 \mathrm{M} \Omega$ s (average: $400 \pm 200 \mathrm{M} \Omega$ s), membrane capacitance ranged between 42 and $158 \mathrm{pF}$ (average: $90 \pm 40 \mathrm{pF}$ ), and membrane resting potential ranged between -70 and $-82 \mathrm{mV}$ (average: $-76 \pm 5 \mathrm{mV})$.

Neuronal type was established based on cell morphology under IR oblique illumination and their firing properties upon suprathreshold current injections of increasing amplitudes up to $350 \mathrm{pA}$ in the currentclamp recording configuration. Cells were inspected visually before patch with a $40 \times$ water-immersion objective. The characteristic AP firing was the main parameter used during recordings to distinguish the type of cells. The firing of pyramidal cells shows a classic spike frequency adaptation and the maximal frequency of firing is close to $20 \mathrm{~Hz}$; the second AP in a series is wider than the first, and the development of an adaptive hump as the cell is further depolarized can be often observed. Most interneurons were fast spiking, which show almost no adaptation in their firing, their AP characterized by a big component of the fast after-hyperpolarization and with frequencies well beyond $20 \mathrm{~Hz}$ (Cauli et al., 2000). A few cases $(n=3)$ were regular spiking nonpyramidal or stuttering interneurons.

\section{Photostimulation procedure}

Two different approaches were used to search for cells expressing the Chronos opsin. In most of the experiments expression was sparse and it was then relatively simple to detect single-transfected cells through widefield fluorescence illumination. In cases of higher expression, in which the background fluorescence was too high, we used the $2 \mathrm{P}$ imaging. In regions of really high levels of expression, we instead adopted the option of blindly patched cells, and their level of expression was verified by electrical recordings of the currents evoked by photostimulation. Recorded cells were monitored through IR oblique light illumination during the patching phase.

Photostimulation of $\mathrm{CHO}$ cells. $2 \mathrm{P}$ photocurrents were evoked while maintaining the cell in voltage-clamp configuration at $-40 \mathrm{mV}$. For the characterization of the current response as a function of the light power density, a holographic shape completely covering the cell surface was used. In this way, all channels fell within the illuminated area and we could avoid problems of spurious recruitment of channels outside of the holographic pattern as the power increases.

The experiments to characterize the spectral response of Chronos were performed on a different setup equipped with a tunable Ti:Sapphire laser and with a GPC holographic illumination delivering large-diameter spots that covered the whole cell (Papagiakoumou et al., 2010; Chaigneau et al., 2016).

Photostimulation of neuronal cells. Recorded cells were photostimulated with $2 \mathrm{P}$ holographic spots of 10-20 $\mu \mathrm{m}$ diameter centered on the soma of the cell. The duration and intensity of the stimulus varied depending on the experimental procedure and are indicated in the results. The value of the power density used during the stimulation was calculated as the ratio of the laser power measured after the objective and the surface of the designed spot.

\section{Data acquisition}

For the experiments on spectral characterization, electrical signals were recorded through a Multiclamp 700B patch-clamp amplifier and digitized using a Digidata 1322A interface and pClamp software (Molecular Devices). All other recordings were performed using a Multiclamp 700B patch-clamp amplifier and digitized using a National Instruments data 
a

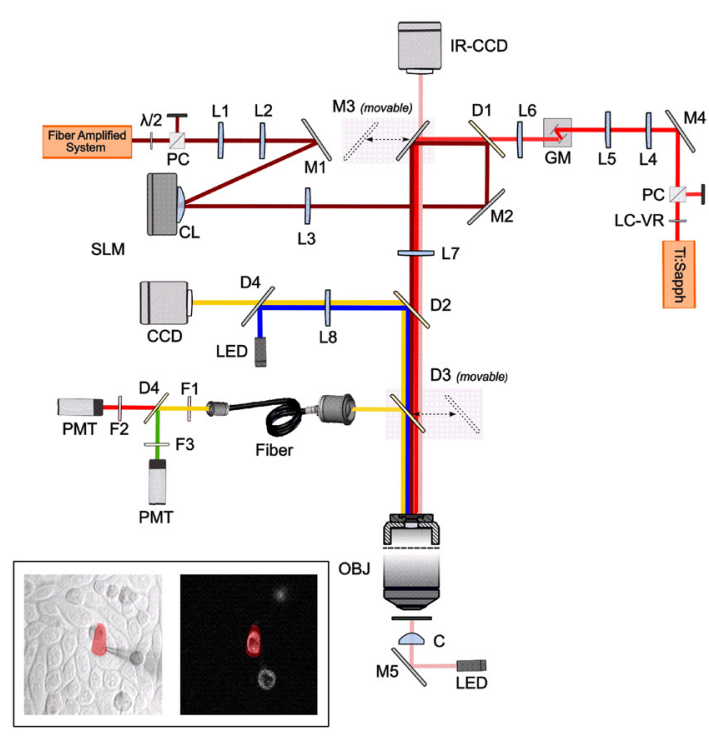

b

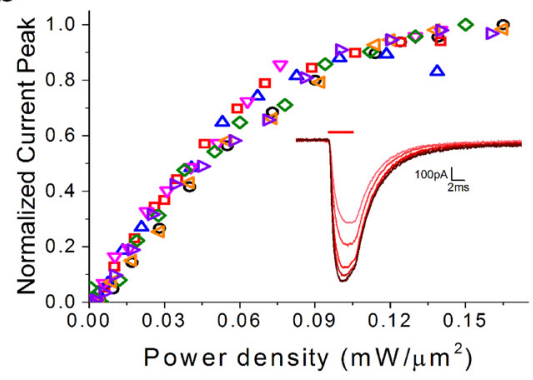

d

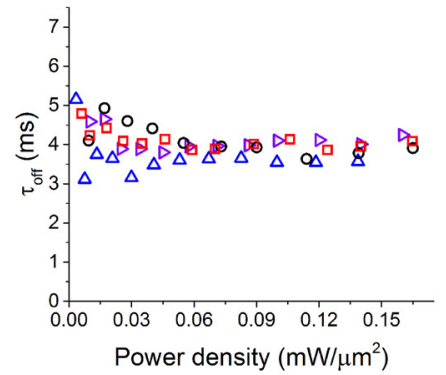

C
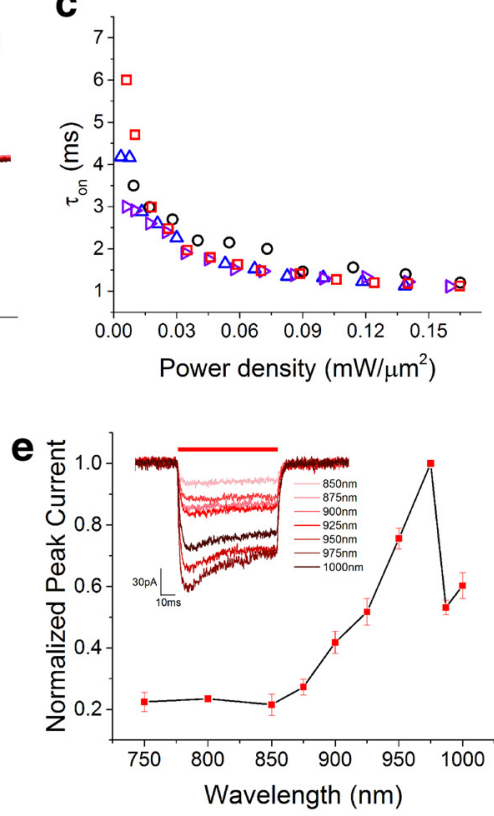

Figure 1. Chronos $2 \mathrm{P}$ kinetics and spectra. $a, 2 \mathrm{P}$ holographic photostimulation and $2 \mathrm{P}$ scanning imaging optical setup. $\mathrm{PC}$, polarizer cube; $\lambda / 2$, half-wave plate; $M$, mirror; $L$, lens; $\mathrm{CL}$, cylindrical lens; D, dichroic; LC-VR, liquid crystal variable retarder; GM, galvanometric mirrors; F, filter; OBJ, objective; C, condenser. Inset, IR-transmitted (left) and 2P fluorescence (right) images of Chronos-expressing $\mathrm{CHO}$ cells. A patched cell is photostimulated by a holographic illumination pattern matching its surface (red pattern). $\boldsymbol{b}$, Normalized peak photocurrent ( $n=6$ cells) over different illumination power densities. Inset, Representative photocurrents generated by irradiating a Chronos-expressing $\mathrm{CHO}$ cell with different illumination power densities $(p=0.04,0.06,0.09,0.1,0.12$, $0.14 \mathrm{~mW} / \mu \mathrm{m}^{2} ; \Delta t=4 \mathrm{~ms} ; \lambda=1030 \mathrm{~nm}$ ). $\boldsymbol{c}, \boldsymbol{d}, 0 \mathrm{n}$ kinetics ( $\boldsymbol{c}$; measured as time to $90 \%$ of the peak) and off kinetics over different illumination power densities (d; $n=4$ cells; different symbols and colors correspond to different cells). $\boldsymbol{e}$, Chronos $2 \mathrm{P}$ action spectra (data are shown as mean \pm SEM; $n=4$ cells). Inset, Representative photocurrents generated by irradiating a Chronosexpressing $\mathrm{CHO}$ cell with different illumination wavelengths using equal photon flux.

acquisition board (\#USB-6259). NeuroMatic software environment in conjunction with IgorPro software (Wavemetrics) were used for data acquisition and analysis. Results are quoted as mean \pm SD unless otherwise specified in the text. Voltage- and current-clamp recordings were filtered at $10 \mathrm{kHz}$ and sampled at $50 \mathrm{kHz}$.

\section{Results}

\section{Photophysical properties of Chronos under 2P illumination}

To determine Chronos kinetic parameters and wavelength sensitivity under 2P, we used $\mathrm{CHO}$ cultured cells transfected with a plasmid encoding GFP-tagged Chronos. We used extended 2P holographic patterns (Lutz et al., 2008; Papagiakoumou et al., 2008) shaped over the cell's surface to photoactivate Chronos-expressing cells and whole-cell patch-clamp recordings to measure the light-induced ionic currents (Figure $1 a$, inset). A high-energy pulse, ultrafast fiber amplifier laser at $\lambda=1030 \mathrm{~nm}$ (see Materials and Methods for details) acted as the photostimulation source, allowing illumination at high peak powers and low average powers.

Initially, we studied the amplitude and kinetics of the photocurrents elicited by photostimulating with short light pulses of varying power densities. The dependence of the photocurrent peak on the illumination power density shows the typical behavior characterized by a nonlinear regime at low power and a saturation phase at high power $\left(>0.15 \mathrm{~mW} / \mu \mathrm{m}^{2}\right)$ (Rickgauer and Tank, 2009; Prakash et al., 2012; Chaigneau et al., 2016) (Fig. 1b). Interestingly, the fast photo cycling of Chronos leads to saturation power levels nearly three times higher than for the slow opsin ReaChR (Chaigneau et al., 2016). As reported previously under $1 \mathrm{P}$ activation (Klapoetke et al., 2014), the temporal dependence of Chronos 2P photocurrents reveals unprecedented fast on and off rates (Fig. $1 c, d)$. The $2 \mathrm{P}$ turn-on time $\left(\tau_{\text {on }}\right)$ diminishes by increasing the illumination power (Fig. 1c) and reaches a value of $1.2 \pm 0.1 \mathrm{~ms}(n=4$ cells $)$ at powers near the saturation regime, whereas $\tau_{\text {off }}$ is almost independent of the illumination power and equal to $3.8 \pm 0.2 \mathrm{~ms}$ (Fig. $1 d$ ).

We then examined Chronos spectral responses by measuring the amplitude of the photocurrents elicited at various illumination wavelengths (Fig. 1e). In this case, we used an optical system equipped with a tunable Ti:Sapphire laser as photostimulation source combined with GPC to generate illumination spots entirely covering the cell (see Materials and Methods) (Papagiakoumou et al., 2010; Chaigneau et al., 2016). Photon flux was maintained constant across wavelengths for each cell, ranging between 1.7 and $2.4 \times 10^{26}$ photons $/ \mathrm{m}^{2} \mathrm{~s}$. Within the range of tunable wavelengths $(750-1000 \mathrm{~nm})$, the $2 \mathrm{P}$ action spectrum shows an absorption bandwidth between 850 and $1000 \mathrm{~nm}$, peaking at 975 nm (Fig. 1e).

\section{P chronos spiking}

To assess the spiking fidelity of Chronos-expressing neurons under $2 \mathrm{P}$ illumination in brain slices at various irradiances and frequencies, we injected layer $2 / 3$ of visual cortex of 4 -week-old Swiss mice with adeno-associated virus rAAV8/Synapsin-ChronosGFP. Slices were prepared 6-8 weeks after injection. We photoactivated Chronos-expressing neurons by illuminating the soma of the cells with $2 \mathrm{P}$ holographic circular spots $(10-15 \mu \mathrm{m}$ spot diameter; $\lambda=1030 \mathrm{~nm}$, fiber amplifier laser system). We recorded cellular activity by whole-cell patch clamp (Fig. $2 a$ ).

To demonstrate the achievable temporal precision at high firing rates, we mainly focused the analysis and recordings on fast spiking interneurons. Firing properties of slow-spiking cells (pyramidal) were also investigated (Table 1).

In voltage clamp, photocurrents of hundreds of picoamperes were evoked upon somatic photostimulation at moderate power density levels $\left(I=415 \pm 213 \mathrm{pA}, p=0.08 \pm 0.02 \mathrm{~mW} / \mu \mathrm{m}^{2}\right.$; 
a

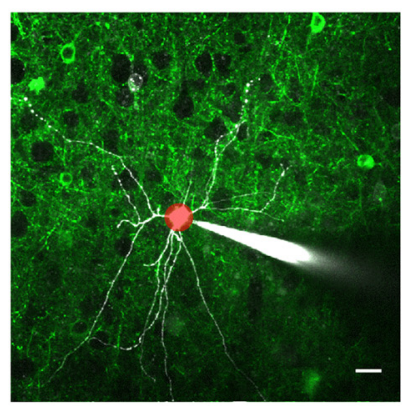

d

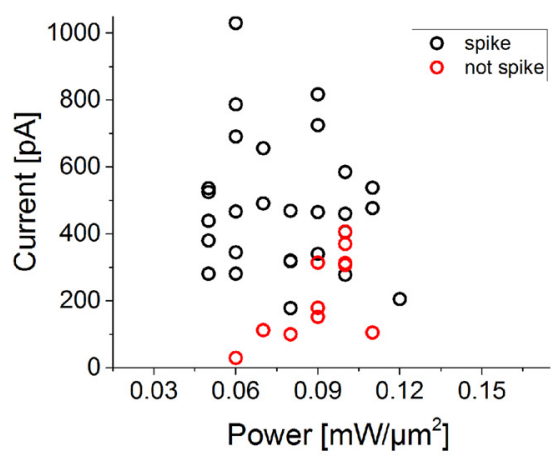

b

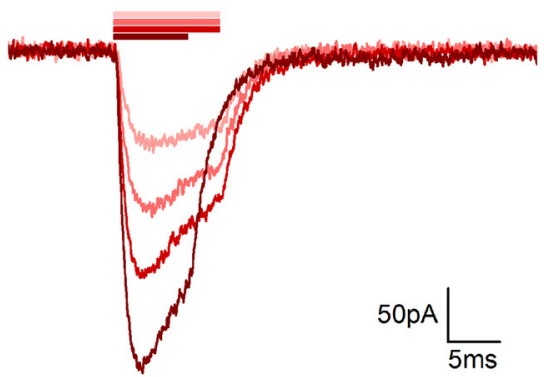

e

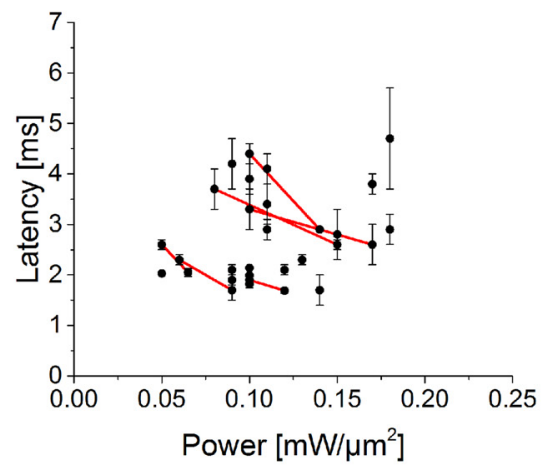

c
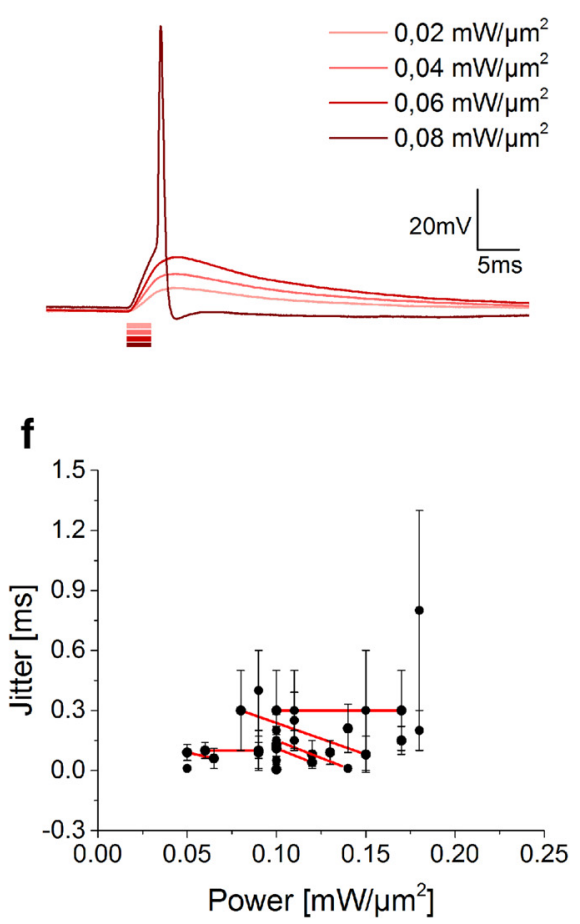

Figure 2. 2P activation of Chronos-expressing interneurons. a, 2P image of a portion of an acute cortical brain slice of a virus-injected mouse. A patched/Alexa Fluor 594 -filled (white) interneuron of layer 2/3 expressing Chronos-GFP (green) is photostimulated by a $10 \mu \mathrm{m}$ holographic spot (red spot). Scale bar, $20 \mu \mathrm{m}$. $\boldsymbol{b}, \boldsymbol{c}$, Representative light-evoked photocurrents ( $\boldsymbol{b}$ ) and membrane potential depolarization (c) over different illumination powers in a Chronos-expressing interneuron. $\boldsymbol{d}$, Light-evoked currents in spiking (black) and nonspiking (red) neurons for power densities between 0.05 and $0.12 \mathrm{~mW} / \mu \mathrm{m}^{2}$. Each circle corresponds to one cell. $\boldsymbol{e}, \boldsymbol{f}$, Latencies (e; calculated from the start of the light pulse to the spike depolarization threshold) and jitter $(\boldsymbol{f} ;$ calculated as mean deviation of latency) of light-evoked spikes ( $n=24$ cells) by 10 - to $15-\mu$ m-diameter spots (data are shown as mean \pm SD). Red lines connect data from same cells.

Table 1. Resuming currents and spiking probability of Chronos-expressing neurons photoactivated by illuminating the cellular soma with circular 2P holographic spots

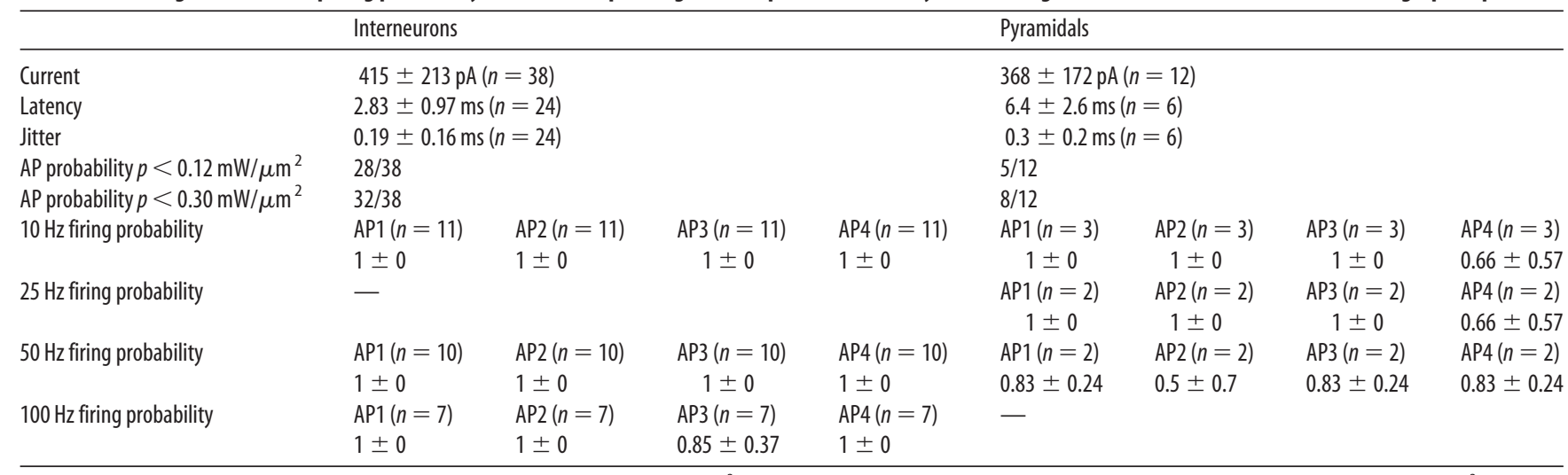

Interneurons: spot diameter $10-15 \mu \mathrm{m}$, illumination duration 2-3 ms, power range: $0.05-0.17 \mathrm{~mW} / \mu \mathrm{m}^{2}$. Pyramidal cells: spot diameter $15-20 \mu \mathrm{m}$, illumination duration 3-10 ms, power range: $0.09-0.16 \mathrm{~mW} / \mu \mathrm{m}^{2}$.

mean $\pm \operatorname{SD}$ on $n=38$ interneurons; Fig. $2 b, d)$. In current clamp, generation of single APs was obtained using 2-3 ms irradiation durations (Fig. $2 c$; cells successfully photoeliciting single AP: $74 \%$ for $p<0.12 \mathrm{~mW} / \mu \mathrm{m}^{2}$; $84 \%$ for $p<0.3 \mathrm{~mW} / \mu \mathrm{m}^{2}, n=38$ interneurons). In a few cases of highly expressing cells (peak photocurrent in voltage clamp $I=817 \pm 315 \mathrm{pA}, p=0.08 \pm 0.02$ $\mathrm{mW} / \mu \mathrm{m}^{2}, n=5$ cells), we could shorten the stimulation pulse and still obtain AP generation with $1 \mathrm{~ms}(n=2$ cells, APs evoked in $3 / 3$ photostimulation trials per cell) and $0.7 \mathrm{~ms}(n=3$ cells, APs evoked in $3 / 3$ photostimulation trials per cell) pulse duration $\left(p=0.13 \pm 0.05 \mathrm{~mW} / \mu \mathrm{m}^{2}\right)$. APs occurred with short latencies $\left(2.83 \pm 0.97 \mathrm{~ms}, p=0.11 \pm 0.03 \mathrm{~mW} / \mu \mathrm{m}^{2}\right.$; mean \pm SD. on $n=$ 24 cells, Fig. $2 e$ ) and submillisecond temporal precision (jitter
$0.19 \pm 0.16 \mathrm{~ms}, p=0.11 \pm 0.03 \mathrm{~mW} / \mu \mathrm{m}^{2}$; mean $\pm \mathrm{SD}$. on $n=$ 24 cells, Fig. $2 f$ ). Increasing the illumination power enabled reducing spike latency and jitter (see line-connected cells in Fig. $2 e, f)$.

The ability to evoke precisely timed, high-frequency spike trains demands that the following conditions are satisfied: short light-evoked AP latency, small jitter, and opsins featuring fast off kinetics and recovery from inactivation. In particular, lightevoked AP latency, determined in large part by the optical stimulation method (i.e., scanning vs holography) imposes a hard limit on the maximum spike actuation frequency. In practice, 100 $\mathrm{Hz}$ spike actuation requires latencies well $<10 \mathrm{~ms}$. The lightgated channel off time determines the minimum delay between 
two light-evoked APs necessary to fully repolarize the neuron. Recovery from inactivation determines the time necessary to make all opsins available again after a photostimulation pulse. These minimum delays guarantee that the neuron responds to each photostimulus in the very same manner, thus ensuring consistent responses and avoiding artifactual spike doublets or plateau potentials. Finally, the light-evoked AP jitter determines the time precision of light-driven firing. Our holographic actuation of Chronos is the first $2 \mathrm{P}$ optical system to satisfy all of these conditions.

To verify that high-frequency precisely timed spiking can be driven in Chronos-expressing neurons under $2 \mathrm{P}$ holographic illumination, we photostimulated with trains of light pulses (2-3 ms pulse width) at different frequencies neurons that successfully elicited a single AP. We found that $2 \mathrm{P}$ light stimulation could drive cells to spike up to a frequency of $100 \mathrm{~Hz}$ (Fig. 3a). 2Pdriven spiking (with no failures) was achieved up to a stimulation frequency of $50 \mathrm{~Hz}$, whereas spike failures might be encountered at $100 \mathrm{~Hz}$ stimulation frequency after 3-4 pulses depending on the Chronos expression level and the cell type (Fig. 3b). Contrary to what was obtained for slower opsins (Chaigneau et al., 2016), we observed only small plateau potentials even at high stimulation frequencies, indicating fast repolarization between illumination pulses (Gunaydin et al., 2010; Fenno et al., 2011). Furthermore, no asynchronous spikes were evoked and a modest increase of spike latency and jitter throughout the succession of photostimulations was recorded (Fig. 3c,d). Both observations confirm the high spike temporal precision of Chronos when driven by $2 \mathrm{P}$ patterned light during sustained stimulation of short light pulses. Importantly, due to the short pulse duration and relatively small amount of light necessary to trigger an AP, a prolonged series of photostimulations did not induce physiological damage detectable with whole-cell patch clamp. In a series of experiments $(n=$ 5 cells), we tested cell stability during several minutes of successive series of 10 light pulses delivered at $10 \mathrm{~Hz}$ every $6 \mathrm{~s}$. The AP amplitude, input resistance, and membrane potential did not change appreciably during 40 consecutive train stimulations (average AP amplitude: $99 \pm 4 \mathrm{mV}$; AP amplitude variation: $0.8 \pm$ $0.4 \mathrm{mV}$; input resistance: $143 \pm 17 \mathrm{M} \Omega$; input resistance variation $0 \pm 6 \%$; membrane potential variation: $0.9 \pm 0.8 \mathrm{mV}$; Fig. $3 e$ ). Spike latencies showed modest augmentation during successive trains of photostimulation, suggesting that the proportion of inactivated channels gradually increased during photostimulation sustained over minutes (Fig. $3 f$ ).

To assess the importance of fast kinetics for precisely timed, high-frequency spike stimulation, we compared the spiking performance of holographically actuated Chronos-expressing neurons with neurons expressing the slower opsin $\operatorname{CoChR}\left(\tau_{\text {on }} \approx 2.4 \mathrm{~ms}\right.$ and $\tau_{\text {off }} \approx 30 \mathrm{~ms}$; Papagiakoumou et al., 2017) under the same experimental conditions. We injected layer $2 / 3$ of visual cortex of 4-week-old Swiss mice with adeno-associated virus AAV8/ Synapsin-CoChR-GFP. In the CoChR-expressing interneurons, 1-3 ms illumination pulses produced single AP spike latency and jitter comparable to those of Chronos (CoChR AP latency: $4.76 \pm$ $0.57 \mathrm{~ms}$, AP jitter: $0.15 \pm 0.05 \mathrm{~ms} ; p=0.09 \pm 0.03 \mathrm{~mW} / \mu \mathrm{m}^{2}$; mean $\pm \mathrm{SD}$. on $n=4$ cells), corroborating the fact that, under 2P-CGH photostimulation, short light-evoked AP latency and jitter can be enabled independently both in fast and slow opsins (Chaigneau et al., 2016). We then assessed photostimulation with high-frequency illumination pulses. We could evoke spiking up to $50 \mathrm{~Hz}$ with high fidelity (Fig. $4 a-d$ ), although with higher plateau potential compared with Chronos. The spike rate could be increased above $50 \mathrm{~Hz}$ by increasing the frequency of the light stimulation train. However, depending on illumination power and pulse duration, light-driven spiking fidelity appeared distorted, exhibiting low synchronicity between the light pulses and spiking, missed APs, generation of extra spikes or plateau potentials, all indicating insufficient repolarization between consecutive pulses. In particular, tuning neither the illumination power nor the pulse duration could control spike timing and firing fidelity precisely (Fig. 4e). The analysis of the same type of photostimulation conducted in $\mathrm{CHO}$ cells further emphasized the limitations of high-frequency light-driven photostimulation combined with slow turn-off opsins. In CoChR-expressing $\mathrm{CHO}$ cells, photo-evoked currents decayed to zero between light pulses only for low-frequency stimulations $(10 \mathrm{~Hz})$, whereas significant current summation resulted for consecutive stimuli for higher photostimulation rates ( 50 and $100 \mathrm{~Hz}$; Fig. $4 f$ ). Conversely, photocurrents evoked during high-frequency light-train stimulation of Chronos-expressing $\mathrm{CHO}$ cells decayed rapidly to baseline levels after each illumination without significantly affecting the following stimuli (Fig. 4f).

Finally, because combining optical photostimulation with $2 \mathrm{P}$-scanning $\mathrm{Ca}^{2+}$ imaging is a practice of wide interest for optogenetic studies, we investigated the activity induced on Chronos-expressing interneurons during $2 \mathrm{P}$ scanning of a large field of view (FOV). We performed whole-cell patch-clamp recordings of membrane potential variations in Chronos-expressing interneurons during $2 \mathrm{P}$ raster scanning of a $920 \mathrm{~nm}$ femtosecond beam typically used for imaging genetically encoded calcium indicators (GCaMPs). In particular, we tested cell depolarization while performing $2 \mathrm{P}$ scanning imaging (Fig. 5) using two FOVs $\left(294 \times 294 \mu \mathrm{m}^{2}\right.$ and $\left.147 \times 147 \mu \mathrm{m}^{2}\right)$ at different frame rates obtained by maintaining constant time per line and varying the number of lines ( $n=6$ cells). Cell depolarization augments by increasing the illumination power and the number of lines (i.e., reducing the interline distance and thus augmenting the sampling density of the scanned beam on the cell) or reducing the imaging FOV (i.e., increasing the fraction of time during which the scanned beam illuminates the cell and thus augmenting the duty-cycle of the scanned beam on the cell). Although the majority of cells showed modest depolarizations $(<5 \mathrm{mV})$, significantly higher depolarizations were observed under certain illumination conditions in two of six interneurons. Although Chronos's fast off-kinetics may render it less vulnerable to spurious actuation during imaging scans compared with slower opsins, these results indicate that particular care is still needed when imaged with standard galvanometric mirror scanning regimes for calcium indicators such as GCaMP. Further work is needed to minimize such artifacts, in particular to identify high signal-to-noise fluorescence reporters with $2 \mathrm{P}$ spectra that overlap less with that of Chronos.

\section{Discussion}

We have demonstrated optical control of neuronal firing up to $100 \mathrm{~Hz}$ with submillisecond AP onset precision in acute cortical slices with soma-targeted $2 \mathrm{P}$ holographic illumination.

Millisecond temporal control of neuronal firing opens the door to spatially and temporally mimicking neural activity patterns, which is critical for studying how spike temporal and rate codes convey information in the brain (Lisman, 1997; Izhikevich et al., 2003; Baranauskas, 2015), refine reverse-engineering neural circuits programs (O'Connor et al., 2009), as well as closedloop and activity-guided perturbation of neural dynamics and behavior (Grosenick et al., 2015). Precise spike timing and highfrequency neural events have been linked to many relevant 
a

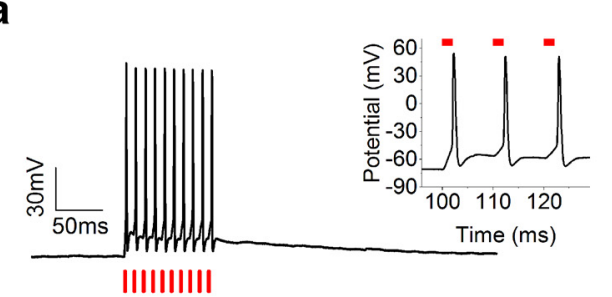

IIIIIIIII

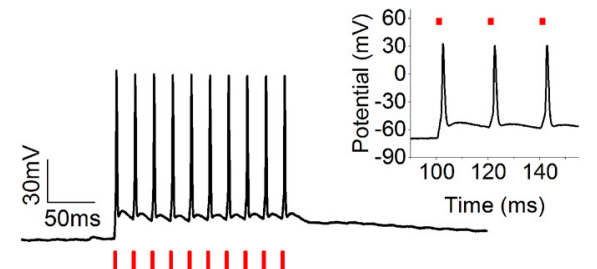

b
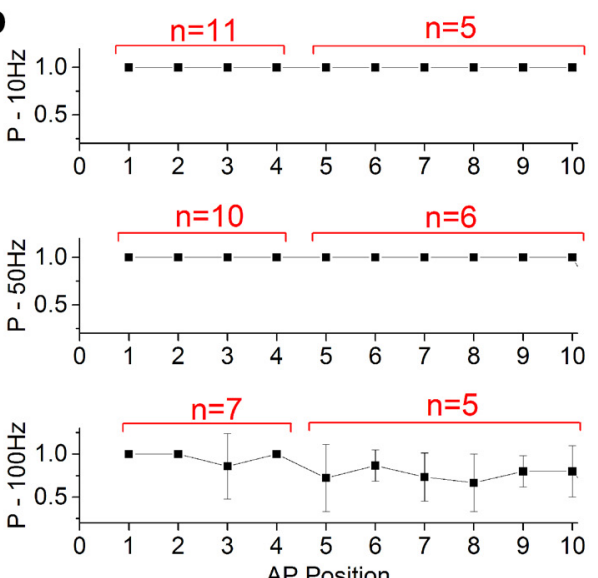

AP Position
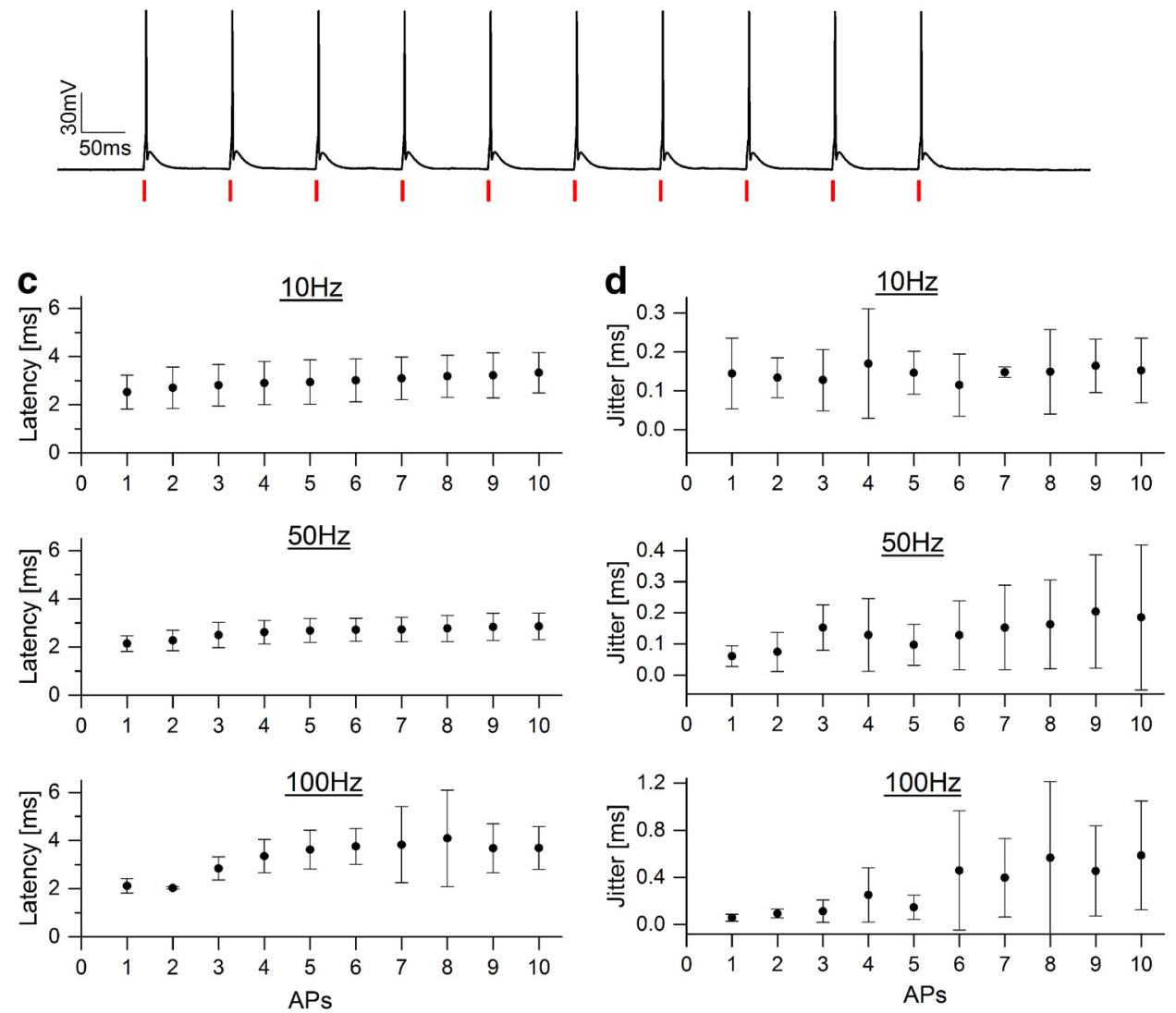

e
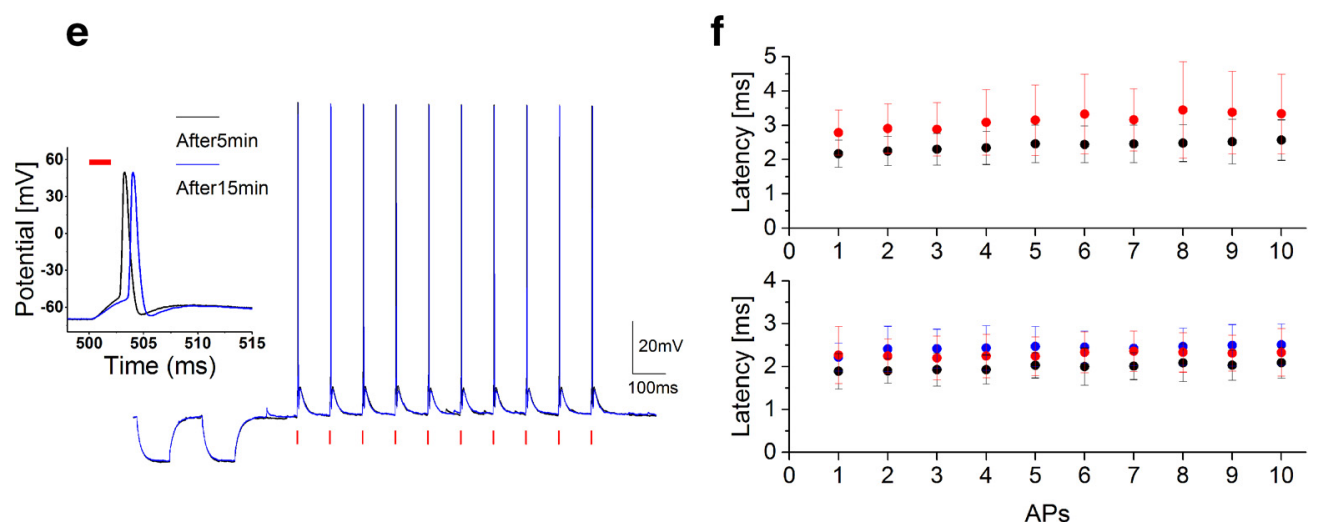

Figure 3. Light-driven spiking fidelity across different frequencies in Chronos-expressing interneurons. $\boldsymbol{a}$, Sample trains of 10 photostimulation pulses of 2 ms duration each over different frequencies: $10 \mathrm{~Hz}, p=0.09 \mathrm{~mW} / \mu \mathrm{m}^{2}$ (bottom); $50 \mathrm{~Hz}, p=0.09 \mathrm{~mW} / \mu \mathrm{m}^{2}$ (middle); $100 \mathrm{~Hz}, p=0.12 \mathrm{~mW} / \mu \mathrm{m}^{2}$ (top). $\boldsymbol{b}$, Spike probability within the 10 pulses (cells have been photostimulated either with four or 10 light-pulse trains; red shows the number of cells in which the i-th spike has been tested). $\boldsymbol{c}$, $\boldsymbol{d}$, Latency (c) and jitter (d) of each light-evoked (Figure legend continues.) 


\section{a}
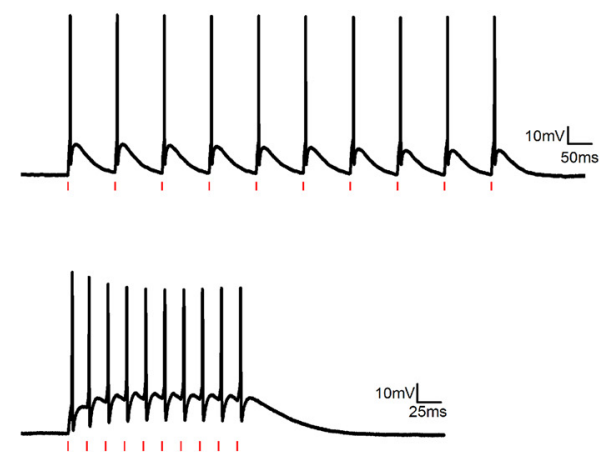

C
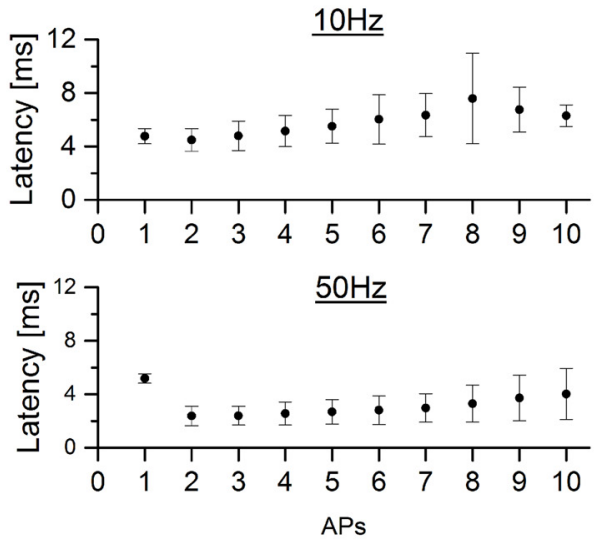

e
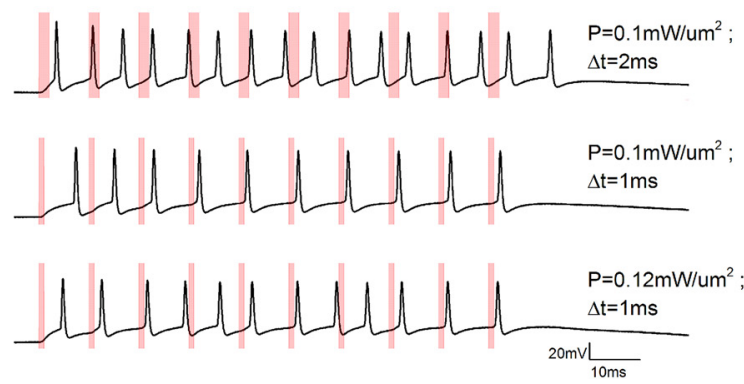

b
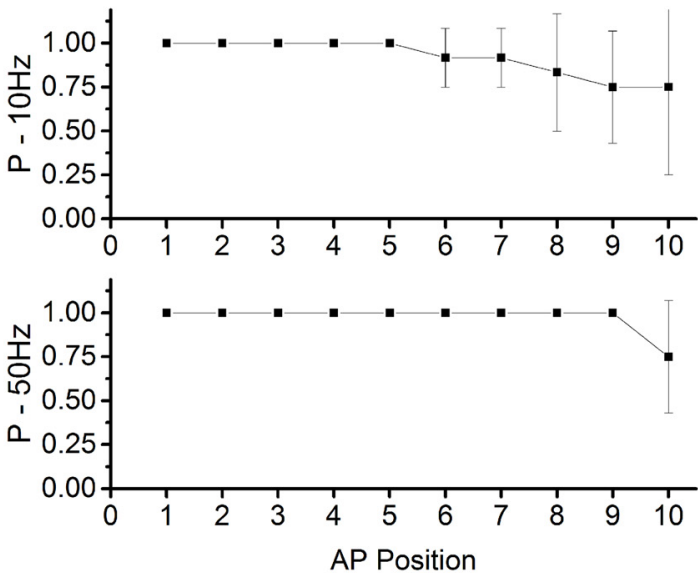

d
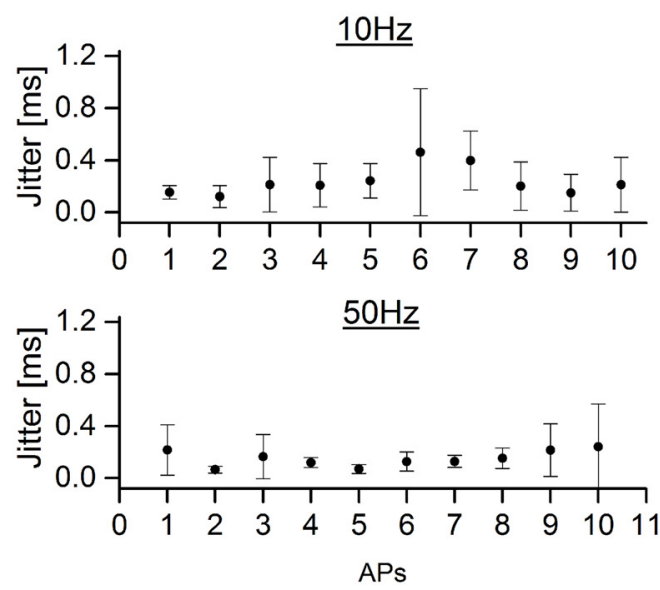

$\mathbf{f}$
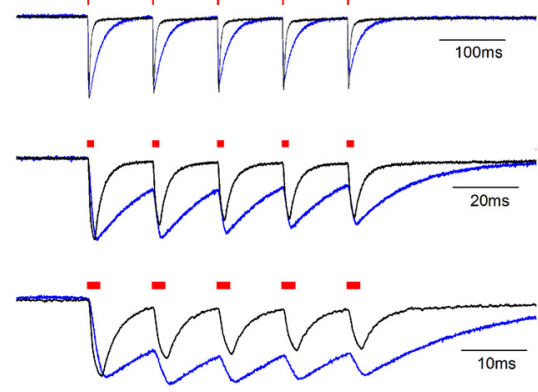

Figure 4. Light-driven spiking fidelity across different frequencies in CoChR-expressing interneurons. $\boldsymbol{a}$, Representative light-driven firing induced by a train of 10 illumination pulses at (top) $10 \mathrm{~Hz}$ ( $p=0.1 \mathrm{~mW} / \mu \mathrm{m}^{2}$; pulse width $2 \mathrm{~ms}$; spot diameter $15 \mu \mathrm{m}$ ) and (bottom) $50 \mathrm{~Hz}$ ( $p=0.12 \mathrm{~mW} / \mu \mathrm{m}^{2}$; pulse width $1 \mathrm{~ms}$; spot diameter $15 \mu \mathrm{m}$ ). $\boldsymbol{b}$, Spike probability within the 10 pulses for illumination at $10 \mathrm{~Hz}$ (top) and $50 \mathrm{~Hz}$ (bottom; $n=4$ ). $\boldsymbol{c}, \boldsymbol{d}$, Latency (c) and jitter (d) of each light-evoked spike of the train. Illumination power range: $0.05-0.12 \mathrm{~mW} / \mu \mathrm{m}{ }^{2}$, $1-3 \mathrm{~ms}$ illumination pulse duration, $15 \mu$ m diameter spot, $\lambda=1030 \mathrm{~nm}$. Data are shown as mean $\pm \mathrm{SD}(n=4)$. $\boldsymbol{e}$, Representative light-driven firing induced by a train of 10 illumination pulses at $100 \mathrm{~Hz}$ using different power and pulse width durations. $f$, Representative normalized photocurrents evoked illuminating with five pulses ( 2 ms pulse width) at different frequencies (hronos-expressing (black) and a CoChR-expressing (blue) $\mathrm{CHO}$ cells (top: $10 \mathrm{~Hz}$, middle: $50 \mathrm{~Hz}$, and bottom: $100 \mathrm{~Hz}$ ).

phenomena in neural plasticity, behavior, and pathology, including setting the direction of synaptic change in spike-timingdependent plasticity (Dan and Poo, 2004), mediating neural coding in systems such as the auditory system (Köppl, 1997), and

\section{$\leftarrow$}

(Figure legend continued.) spike of the train. Illumination power range: $0.05-0.17 \mathrm{~mW} / \mu \mathrm{m}^{2}$, 2-3 ms illumination pulse duration, $10-15 \mu \mathrm{m}$ diameter spot, $\lambda=1030 \mathrm{~nm}$. Data are shown as mean \pm SD.e, Trains of 10 pulses at $10 \mathrm{~Hz}$ triggered every $6 \mathrm{~s}$ after 5 min (black line) and after $15 \mathrm{~min}$ (blue) preceded by resistance steps. $\boldsymbol{f}$, Latencies of each light-evoked spike within the train after $0 \mathrm{~min}$ (black) and $3.5 \mathrm{~min}$ (red; Top, $n=5$ cells) and $0 \mathrm{~min}$ (black), $3.5 \mathrm{~min}$ (red), and 7 min (blue; bottom, $n=3$ cells). contributing to functions altered in diseases such as Parkinson's disease (Foffani et al., 2003). Some cell types such as parvalbuminpositive interneurons fire at high frequencies and the loss of such neurons may be a contributor to psychiatric illness (Behrens et al., 2007). Fast patterns of neural spiking may also govern whether spikes propagate throughout dendrites and thus affect localized cellular processes (Buzsáki et al., 1996).

The achieved high temporal precision depends on a combination of factors inherent to the opsin Chronos in combination with the holographic light-shaping approach. The ability to drive high-frequency firing optically without introducing spurious artifacts (i.e., spike multiplets or plateau potentials) arises from two 
a
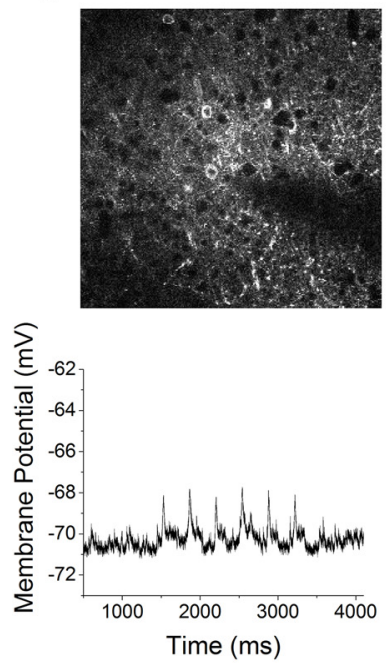

b

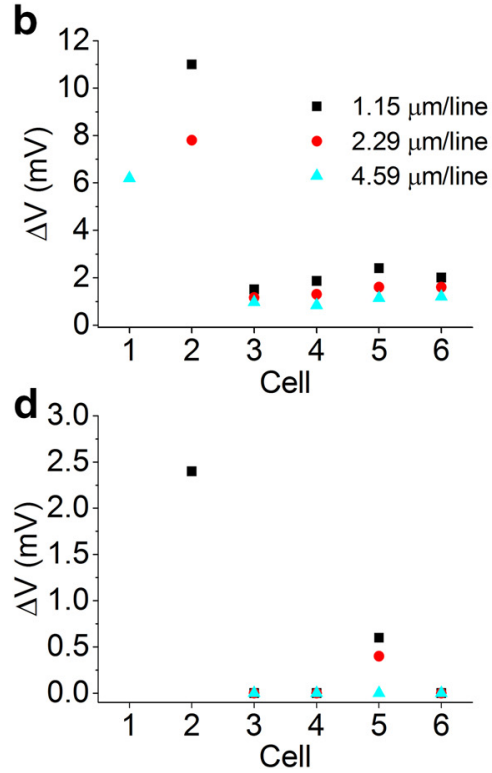

C

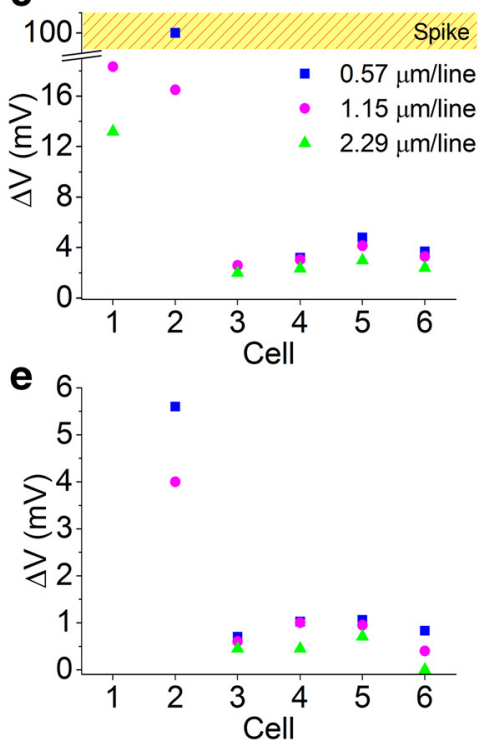

Figure 5. Scanning imaging effects on Chronos-expressing interneurons. $\boldsymbol{a}, 2 \mathrm{P}$ image of a patched Chronos-exressing neuron of acute cortical brain slices acquired by raster scanning a $920 \mathrm{~nm}$ femtosecond beam (FOV $294 \mu \mathrm{m} ; 1.15 \mu \mathrm{m} /$ line; $2.96 \mathrm{~Hz}$ frame rate; $p=14 \mathrm{~mW}$; top); corresponding membrane potential depolarization is shown at bottom. $\boldsymbol{b}$ - $\boldsymbol{e}$, Membrane depolarizations obtained on different cells by raster scanning a $920 \mathrm{~nm}$ beam over $294 \mu \mathrm{m}(\boldsymbol{b}, \boldsymbol{d})$ and $147 \mu \mathrm{m}(\boldsymbol{c}, \boldsymbol{e})$ with $14 \mathrm{~mW}(\boldsymbol{b}, \boldsymbol{c})$ and $5 \mathrm{~mW}(\boldsymbol{d}, \boldsymbol{e})$ excitation power for various line-scanning resolutions at $1.32 \mathrm{~ms} /$ line.

main factors: (1) the light-evoked AP latency, which determines how quickly an opsin-expressing neuron can be depolarized to spike threshold; and (2) the opsin's off kinetics and inactivation recovery, which determine the time necessary for the neuron to fully repolarize and for all the actuated opsin to recover. Accordingly, short light-evoked AP latency must be reached and fast kinetics opsins adopted. 2P holographic stimulation achieves well the first condition because of spatial summation of current evoked throughout the soma. Moreover, parallel illumination such as $2 \mathrm{P}-\mathrm{CGH}$ is required to actuate spiking in opsins satisfying the second condition because such fast off kinetics likely preclude the temporal summation needed for point-scanning approaches. By reducing light-evoked AP latency and adopting fast kinetic opsins, the natural physiological firing limits of a specific neuron type can in principle be actuated optically. A third fundamental parameter, the jitter of light-evoked APs, describes the AP timing precision and thus the temporal control accuracy of light-driven firing. Here, we evoked spikes holographically with millisecond latency and submillisecond jitter for both Chronos- and CoChRexpressing targeted neurons. In addition, in the case of Chronos, holographic stimulation could actuate spiking up to $100 \mathrm{~Hz}$ because of this opsin's short kinetics.

The low power densities needed for high temporal precision 2P Chronos activation were enabled by the use of a fiber-amplifier low repetition rate laser. The fiber-amplifier laser source $(500 \mathrm{kHz})$ achieves higher $2 \mathrm{P}$ efficiency than typical mode-locked Ti:Sapphire laser oscillators (typically $80-100 \mathrm{MHz}$ ) due to lower pulse repetition rates of the femtosecond beam (2P excited signal, $S \propto P_{a v g}^{2}(f \tau)^{-1}$, where $f$ is the repetition rate, $\tau$ the pulse width, and $P_{\text {avg }}$ the average beam power; $\mathrm{Xu}$ and Webb, 1996; Zipfel et al., 2003). This enabled efficient photo current and spike generation with modest light powers $\left(<0.15 \mathrm{~mW} / \mu \mathrm{m}^{2} ; 12-27 \mathrm{~mW} /\right.$ cell) and short light pulses $(<3 \mathrm{~ms})$, allowing repetitive cell stimulation without affecting electrophysiological parameters. These findings, together with the fact that amplified lasers can deliver high average power beams $(\approx 10 \mathrm{~W}$ at laser output), indi- cate that laser power is not the limiting factor for the maximum achievable number of targets using 2P-CGH.

These results open the door to in vivo light-targeted multineuronal activation with high temporal control and cell-targeted patterned stimulation of entire neuronal networks. The maximum number of neurons that can be stimulated simultaneously will be mainly limited by two elements: the light-induced heating and the deterioration of the photostimulation spatial resolution. Data shown here demonstrate that, in the proposed activation conditions, individual stimulated cells conserve physiological integrity even under sustained train of illuminations, suggesting that thermic effects per cell are kept below damaging threshold. Nevertheless, cumulative heating effects all over the sample need to be evaluated carefully when large and dense groups of neurons are stimulated. Effects of heating can be further compounded by additional light exposure during functional imaging. Further limitations for large-scale multiple-cell stimulation arise from the photostimulation of cellular processes crossing the overall illumination volume. Indeed, illumination of multiple processes of opsin-expressing neurons could likely generate APs in nontargeted cells, thus limiting the maximum number of targets that can be stimulated by maintaining cellular resolution. The use of opsins with expression that is confined genetically to the somatic region of the neurons can provide a critical advantage for excitation of large pools of neurons without spurious activation of nontargeted cells (Shemesh et al., in press; Baker et al., 2016).

It is important to underline that $2 \mathrm{P}$ holographic-based illumination patterns are robust to scattering and well conserve the intensity patterns distribution up to a few hundred microns in depth (Bègue et al., 2013). This ensures that the activation of targeted neurons under 2P-CGH-based illumination will permit obtaining analogous neuronal spiking reliability and temporal control at various depths by simply providing enough illumination power to compensate scattering losses.

Efficient current integration achievable under $2 \mathrm{P}$ parallel photostimulation enables millisecond spike generation and submil- 
lisecond temporal jitter using opsins with significantly slower kinetics (Chaigneau et al., 2016) than Chronos. However, in this case, the slow off kinetics cause a slow repolarization between pulses with consequent extra spikes and pronounced prolonged plateau depolarization, thus significantly hampering the fidelity of high-frequency light-driven spiking (Chaigneau et al., 2016). CoChR exhibits off kinetics nearly 10 times longer than Chronos and our comparison between these opsins in cortical interneurons underlines the importance of short off kinetics for fast, repetitive AP actuation. While CoChR-expressing neurons could exhibit various artifactual responses when photostimulated with high-frequency trains of light, the fast kinetics of Chronos enabled submillisecond timed control of light-driven neural firing up to $100 \mathrm{~Hz}$, with no extra spikes and small plateau potential. Both latency and jitter values were impressively well maintained during high-frequency (up to $100 \mathrm{~Hz}$ ) trains.

We expect that performance similar to the one achieved with Chronos and $2 \mathrm{P}$ holography can be reached by alternative parallel patterning approaches as GPC (Papagiakoumou et al., 2010) or low-NA Gaussian beams (Rickgauer et al., 2014) and/or other fast opsins such as ChETA variants (Gunaydin et al., 2010), although in this last case the inferior light sensitivity (Lin, 2011) will probably require using higher excitation power levels. Also note that the $2 \mathrm{P}$ action spectrum of Chronos revealed that $2 \mathrm{P}$ evoked currents under $1030 \mathrm{~nm}$ excitation are close to $60 \%$ of the absorption peak (@950 nm), making this opsin compatible with stimulation by high-energy amplified lasers emitting around this wavelength.

Finally, we have shown the activity induced in Chronosexpressing interneurons by imaging under conditions similar to what is typically adopted for GCaMP 2P imaging (large FOV, fast and low-resolution scanning). Despite unfavorable temporal integration of photocurrents during scan illumination due to Chronos fast kinetics, in some cases, we recorded significant membrane depolarization. These results suggest that attention needs to be paid to the choice of the imaging conditions when coupling photostimulation and functional imaging investigations. Reduction of membrane depolarizations during functional imaging could be achieved by using more red-shifted calcium indicators with excitation that does not overlap with Chronos absorption spectrum. Further benefits could be obtained by minimizing the imaging beam dwell time on the cell using smart targeted-path scanning schemes (Lillis et al., 2008; Grewe et al., 2011) to define arbitrarily line-scan trajectories or scanless, camera-based detection (Quirin et al., 2014; Yang et al., 2015, 2016; Bovetti et al., 2017) able to minimize the imaging beam dwell time on the cell dendrites and axons.

\section{References}

Baker CA, Elyada YM, Parra A, Bolton MM (2016) Cellular resolution circuit mapping with temporal-focused excitation of soma-targeted channelrhodopsin. Elife 5.

Baranauskas G (2015) Can optogenetic tools determine the importance of temporal codes to sensory information processing in the brain? Front Syst Neurosci 9:174. CrossRef Medline

Bègue A, Papagiakoumou E, Leshem B, Conti R, Enke L, Oron D, Emiliani V (2013) Two-photon excitation in scattering media by spatiotemporally shaped beams and their application in optogenetic stimulation. Biomed Opt Express 4:2869-2879. CrossRef Medline

Behrens MM, Ali SS, Dao DN, Lucero J, Shekhtman G, Quick KL, Dugan LL (2007) Ketamine-induced loss of phenotype of fast-spiking interneurons is mediated by NADPH-oxidase. Science 318:1645-1647. CrossRef Medline

Berndt A, Schoenenberger P, Mattis J, Tye KM, Deisseroth K, Hegemann P, Oertner TG (2011) High-efficiency channelrhodopsins for fast neuronal stimulation at low light levels. Proc Natl Acad Sci U S A 108:75957600. CrossRef Medline
Bovetti S, Moretti C, Zucca S, Dal Maschio M, Bonifazi P, Fellin T (2017) Simultaneous high-speed imaging and optogenetic inhibition in the intact mouse brain. Sci Rep 7:40041. CrossRef Medline

Boyden ES, Zhang F, Bamberg E, Nagel G, Deisseroth K (2005) Millisecondtimescale, genetically targeted optical control of neural activity. Nat Neurosci 8:1263-1268. CrossRef Medline

Buzsáki G, Penttonen M, Nádasdy Z, Bragin A (1996) Pattern and inhibitiondependent invasion of pyramidal cell dendrites by fast spikes in the hippocampus in vivo. Proc Natl Acad Sci U S A 93:9921-9925. CrossRef Medline

Cauli B, Porter JT, Tsuzuki K, Lambolez B, Rossier J, Quenet B, Audinat E (2000) Classification of fusiform neocortical interneurons based on unsupervised clustering. Proc Natl Acad Sci U S A 97:6144-6149. CrossRef Medline

Chaigneau E, Ronzitti E, Gajowa MA, Soler-Llavina GJ, Tanese D, Brureau AY, Papagiakoumou E, Zeng H, Emiliani V (2016) Two-photon holographic stimulation of ReaChR. Front Cell Neurosci 10:234. Medline

Dan Y, Poo MM (2004) Spike timing-dependent plasticity of neural circuits. Neuron 44:23-30. CrossRef Medline

Ducros M, van 't Hoff M, van't Hoff M, Evrard A, Seebacher C, Schmidt EM, Charpak S, Oheim M (2011) Efficient large core fiber-based detection for multi-channel two-photon fluorescence microscopy and spectral unmixing. J Neurosci Methods 198:172-180. CrossRef Medline

Fenno L, Yizhar O, Deisseroth K (2011) The development and application of optogenetics. Annu Rev Neurosci 34:389-412. CrossRef Medline

Foffani G, Priori A, Egidi M, Rampini P, Tamma F, Caputo E, Moxon KA, Cerutti S, Barbieri S (2003) 300-Hz subthalamic oscillations in Parkinson's disease. Brain 126:2153-2163. CrossRef Medline

Gerchberg RW, Saxton WO (1972) A practical algorithm for the determination of phase from image and diffraction plane pictures. Optik (Stuttg) $35: 237-246$

Grewe BF, Voigt FF, van 't Hoff M, Helmchen F (2011) Fast two-layer twophoton imaging of neuronal cell populations using an electrically tunable lens. Biomed Opt Express 2:2035-2046. CrossRef Medline

Grosenick L, Marshel JH, Deisseroth K (2015) Closed-loop and activityguided optogenetic control. Neuron 86:106-139. CrossRef Medline

Gunaydin LA, Yizhar O, Berndt A, Sohal VS, Deisseroth K, Hegemann P (2010) Ultrafast optogenetic control. Nat Neurosci 13:387-392. CrossRef Medline

Hernandez O, Guillon M, Papagiakoumou E, Emiliani V (2014) Zero-order suppression for two-photon holographic excitation. Opt Lett 39:59535956. CrossRef Medline

Izhikevich EM, Desai NS, Walcott EC, Hoppensteadt FC (2003) Bursts as a unit of neural information: selective communication via resonance. Trends Neurosci 26:161-167. CrossRef Medline

Klapoetke NC, et al. (2014) Independent optical excitation of distinct neural populations. Nat Methods 11:338-346. CrossRef Medline

Köppl C (1997) Phase locking to high frequencies in the auditory nerve and cochlear nucleus magnocellularis of the barn owl, Tyto alba. J Neurosci 17:3312-3321. Medline

Lillis KP, Eng A, White JA, Mertz J (2008) Two-photon imaging of spatially extended neuronal network dynamics with high temporal resolution. J Neurosci Methods 172:178-184. CrossRef Medline

Lin JY (2011) A user's guide to channelrhodopsin variants: features, limitations and future developments. Exp Physiol 96:19-25. CrossRef Medline

Lisman JE (1997) Bursts as a unit of neural information: making unreliable synapses reliable. Trends Neurosci 20:38-43. CrossRef Medline

Lutz C, Otis TS, DeSars V, Charpak S, DiGregorio DA, Emiliani V (2008) Holographic photolysis of caged neurotransmitters. Nat Methods 5:821827. CrossRef Medline

O'Connor DH, Huber D, Svoboda K (2009) Reverse engineering the mouse brain. Nature 461:923-929. CrossRef Medline

Packer AM, Peterka DS, Hirtz JJ, Prakash R, Deisseroth K, Yuste R (2012) Two-photon optogenetics of dendritic spines and neural circuits. Nat Methods 9:1202-1205. CrossRef Medline

Packer AM, Russell LE, Dalgleish HW, Häusser M (2015) Simultaneous alloptical manipulation and recording of neural circuit activity with cellular resolution in vivo. Nat Methods 12:140-146. CrossRef Medline

Papagiakoumou E, de Sars V, Oron D, Emiliani V (2008) Patterned twophoton illumination by spatiotemporal shaping of ultrashort pulses. Opt Express 16:22039-22047. CrossRef Medline

Papagiakoumou E, Anselmi F, Bègue A, de Sars V, Glückstad J, Isacoff EY, 
Emiliani V (2010) Scanless two-photon excitation of channelrhodopsin-2. Nat Methods 7:848-854. CrossRef Medline

Papagiakoumou E, Ronzitti E, Chen I, Picot A, Gajowa M, Sroh A, Emiliani V (2017) Two-photon optogenetics by computer generated holography. In: Optogenetics: a roadmap (Stroh A, ed.). New York: Springer.

Peron S, Svoboda K (2011) From cudgel to scalpel: toward precise neural control with optogenetics. Nat Methods 8:30-34. CrossRef Medline

Prakash R, Yizhar O, Grewe B, Ramakrishnan C, Wang N, Goshen I, Packer AM, Peterka DS, Yuste R, Schnitzer MJ, Deisseroth K (2012) Twophoton optogenetic toolbox for fast inhibition, excitation and bistable modulation. Nat Methods 9:1171-1179. CrossRef Medline

Quirin S, Jackson J, Peterka DS, Yuste R (2014) Simultaneous imaging of neural activity in three dimensions. Front Neural Circuits 8:29. CrossRef Medline

Rickgauer JP, Tank DW (2009) Two-photon excitation of channelrhodopsin-2 at saturation. Proc Natl Acad Sci U S A 106:15025-15030. CrossRef Medline

Rickgauer JP, Deisseroth K, Tank DW (2014) Simultaneous cellularresolution optical perturbation and imaging of place cell firing fields. Nat Neurosci 17:1816-1824. CrossRef Medline

Shemesh A, Tanese D, Zampini V, Linghu C, Piatkevich K, Ronzitti E, Papagiakoumou E, Boyden ES, Emiliani V (2017) Temporally precise singlecell resolution optogenetics. Nat Neurosci, in press.
Xu C, Webb WW (1996) Measurement of two-photon excitation cross sections of molecular fluorophores with data from 690 to $1050 \mathrm{~nm}$. J Opt Soc Am B 13:481. CrossRef

Yang SJ, Allen WE, Kauvar I, Andalman AS, Young NP, Kim CK, Marshel JH, Wetzstein G, Deisseroth K (2015) Extended field-of-view and increasedsignal 3D holographic illumination with time-division multiplexing. Opt Express 23:32573-32581. CrossRef Medline

Yang W, Miller JE, Carrillo-Reid L, Pnevmatikakis E, Paninski L, Yuste R, Peterka DS (2016) Simultaneous multi-plane imaging of neural circuits. Neuron 89:269-284. CrossRef Medline

Yizhar O, Fenno LE, Davidson TJ, Mogri M, Deisseroth K (2011a) Optogenetics in neural systems. Neuron 71:9-34. CrossRef Medline

Yizhar O, Fenno LE, Prigge M, Schneider F, Davidson TJ, O'Shea DJ, Sohal VS, Goshen I, Finkelstein J, Paz JT, Stehfest K, Fudim R, Ramakrishnan C, Huguenard JR, Hegemann P, Deisseroth K (2011b) Neocortical excitation/inhibition balance in information processing and social dysfunction. Nature 477:171-178. CrossRef Medline

Zipfel WR, Williams RM, Webb WW (2003) Nonlinear magic: multiphoton microscopy in the biosciences. Nat Biotechnol 21:1369-1377. CrossRef Medline 